\title{
Distance Laboratory Applications ERRL: A Study on Radio Communication in Electronic Field
}

\author{
C.Ç. Aydın*, G. Türkmen*, E. Özyurt**, E. U. Aydn**, N. E. Çağıltay***, M. E. Özbek**, \\ N. Ceren Alparslan**** and A. Kara** \\ *At1lim University/Faculty of Management, Ankara, Turkey \\ **Atılım University/Electrical and Electronics Engineering, Ankara, Turkey \\ ***Atılım University/Computer Engineering, Ankara, Turkey \\ **** Bilkent University/Computer Technology and Information Systems, Ankara, Turkey
}

\begin{abstract}
In the last decade, the effect of internet usage in education is gradually increased. When we look from academic perspective, the new technologies provided alternatives for students learning. As distance education becomes important everyday, the indispensable elements of teaching and education, laboratories must be reachable via remote connection. Consequently, the education that is going to be given to the students will be more flexible with respect to place and time constraints and students can reach laboratory facilities at any time and anywhere not only in lectures and practical hours. In this study, European Remote Radio Laboratory (ERRL) which is a distance remote Radio Frequency (RF) laboratory designed for electrical-electronics students, is described generally. The software architecture, infrastructure and experiment that can be done with a remote connection have been described.
\end{abstract}

Keywords: Remote Laboratory, Virtual Laboratory, ERRL

\section{INTRODUCTION}

Laboratory experience is an important supplement of Electrical Engineering (EE) education. Laboratory works are provided by means of face-to-face training in particular laboratories as a classical method. Face-to-face training may have many limitations both at the provider and at the learner sides [1]. Among the limitations for the provider side, the requirement for more educators and supporting personnel, high establishment and maintenance costs for some of EE laboratories such as the ones covering radio frequency and microwave techniques are well-known [2]. Laboratory works are important supplement of theory in training of engineers and technicians. In most of vocational training schools, there are many radio communications related courses for teaching the theory but not enough laboratory equipment/experiments to support and demonstrate the application of the theory. As a consequence, these courses are supported by practical studies [3]. They also tend to have very limited opportunities to analyze the data collected by means of the experiments mathematically: usually the measurement device itself is unable to deal with a large amount of data. When time constraints do not exist, the students may process the experiment data by use of powerful analysis software tools, gaining a clearer general picture of the functionality of a certain device or a setup [1]. Besides these requirements, educational opportunities that have been offered in e-education environments, made practical opportunities that are given in laboratory environments necessary.

It has been faced with two different approaches in the literature in order to answer these requirements: the virtual labs and the remote labs. The main difference between them is that virtual labs allow running simulations remotely with possible animations of the controlled system [4] while remote labs are laboratories where students can remotely interact with real experiments. Remote laboratory platforms offer users a flexible practice environment without any time limitations and provide efficient use of expensive and sensitive laboratory equipments. On the other hand, virtual lab initiatives involve the simulation of a system on a computer and don't require a physical lab environment but allow the user feel like $\mathrm{s} / \mathrm{he}$ is performing an experiment. Remote laboratory platforms on the other hand, enable the user to control physical lab equipment from a distance via the Internet.

This paper presents the European Remote Radio Laboratory (ERRL) ${ }^{1}$ initiative aims to develop a laboratory platform that provides, with distant access to high technology equipment through Internet, theoretical and particularly practical radio communications training to those groups including technicians and engineers involved in radio communications field of Information and Communication Technologies (ICT) sector. As a transnational laboratory, the ERRL intends to allow its users to perform web-based experiments, and follow course materials in Radio frequency (RF), microwave and communication field, at any place and any time.

Compared to previous remote laboratory applications in electrical and electronics engineering area, the scope and capabilities of ERRL are much wider and serve more sophisticated and diverse objectives. ERRL aims to furnish the qualifications, which are demanded by today's ICT industry. It intends to provide access to modern teaching materials and experiments, complicated and very expensive equipment that are not currently accessible for

\footnotetext{
${ }^{1}$ ERRL Project is supported by Leonardo da Vinci Pilot Program. Web page of the project can be reached from the following hyperlink http://errl.evtek.fi/.
} 
most students, engineers and technicians. Therefore the benefits and utilities provided by ERRL are far more valuable than any remote lab application realized so far. The project has been started in 2007 and as a pilot study, first modules are implemented. It has been planned to finish the rest of the project in the following year and its advantages on education has been predicted.

\section{SOFTWARE INFRASTRUCTURE AND ARCHITECTURE OF ERRL}

\section{A. System Model}

ERRL project, generally arises from a web server that consist of sub units such as laboratory equipments, Workbench Server (WBS) and EPSS (Electronic Performance Support System) software, Java Applets, Learning Management System (LMS) and a user interface as seen in Fig. 1.

\section{A.1 Workbench Server (WBS)}

It is the lowest layer of the system. This software establishes the communication between instruments and the user interfaces through the ERRL database.

\section{A.2 Electronic Performance System (EPSS)}

The EPSS is developed to prepare the learners to be ready for doing experiments with the specific instruments. The EPSS part of the ERRL project has specific instructions for each instrument in the system. The EPSS also covers some initial experiments to help the learner better understand each instrument. However, these initial experiments are designed as simulation of actual experiments and do not work remotely. It uses real data which is previously prepared for that experiment and stored in the database.

\section{Requirements for an EPSS in the ERRL Project}

Main purpose of the ERRL project is to serve several people (students of the universities, engineers and the technicians) all over the world. Accordingly, the background levels of these learners are not the same.

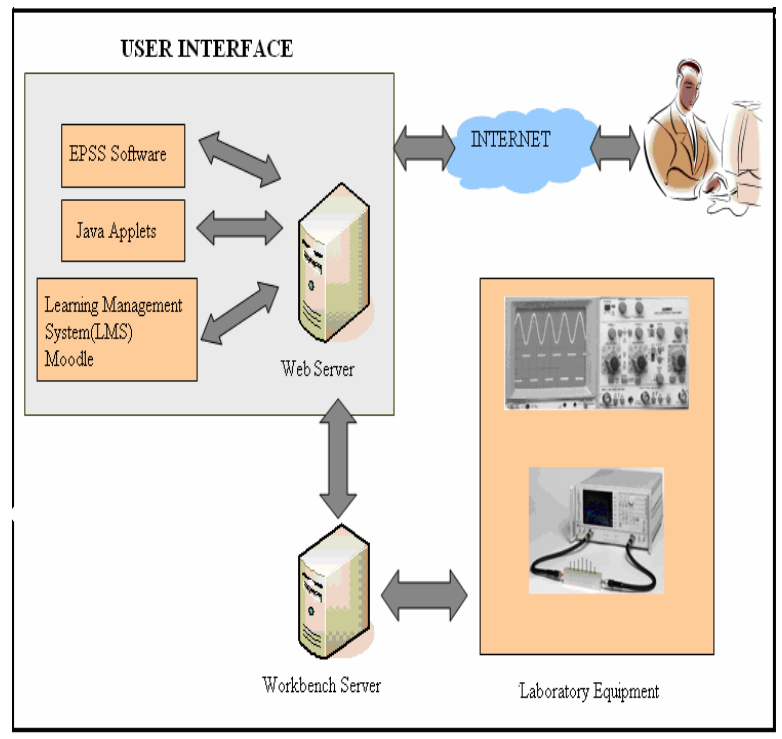

Figure 1.

General Architecture of
This requires a system that provides information for expectations of different learner groups. For example, some learners might be well informed about the equipment but just need to know the meaning of a button or such a little information. On the other hand, others can start learning the equipment for the first time and need any detailed information of the equipment. Accordingly, the system then should provide different levels of information and let its users easily go directly to the requested part.

Some learners will use the equipments while they are doing their daily work in their environment, while other will use the system while doing some experiments on their classes or for their courses. So, the system should be accessible any time while the learners are performing their tasks.

Learners do not need to follow each instruction in the system provided for different equipments. They shall be able to just reach the necessary information which is needed at the moment of the work. So the system must be self-directed and support also nonlinear instructions. Another example is that, if an engineer tries to get some little information about the equipment, and if $\mathrm{s} /$ he has to go through the whole the irrelevant content, it might also be annoying. The system must provide the needed information at the moment of need. On the other hand, the system should also support linear instructions and guidance as well. Because from the requirements analyses we understand that the learners prefer both forms.

The system will be used from different countries. So, it is not clear who and when will use the system. All the learners can connect to the system whenever they want to. Accordingly, the information-base of the system must also be reachable at the time of need. Another issue is that, technology is growing every day. The radio laboratory equipment can also be adapted to the technological changes. The system then can easily be updated according to the technological changes.

In the light of all these necessities, we have decided to develop an Electronic Performance Support System to be able to meet all these requirements. We believe that an EPSS can meet all these requirements.

\section{Integrated Components of EPSS in the ERRL}

ERRL-EPSS includes the following components as shown in Fig. 2. The advisory system builds on a question and answer system between the user and the computer.

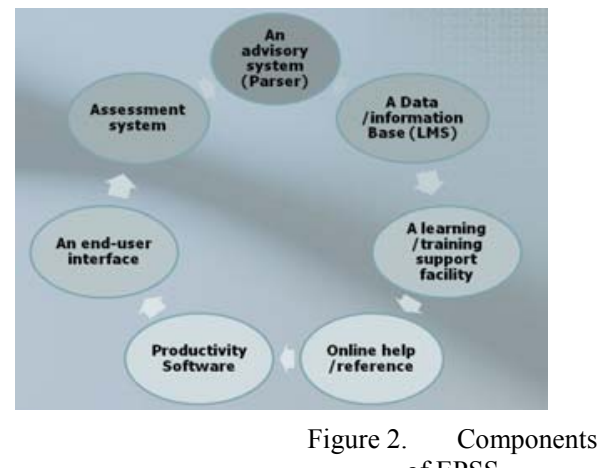
of EPSS 


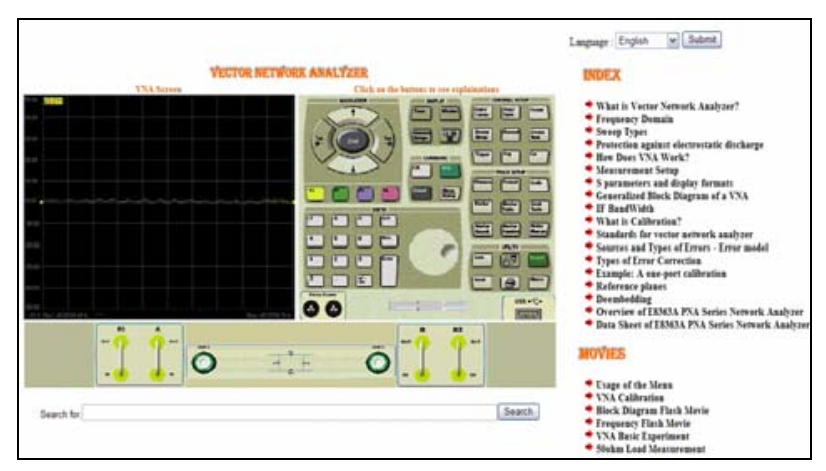

Figure 3. EPSS

By means of a parser, the system gets some questions of learners about the studied equipment. The EPSS parses them and returns some advice in different formats. The advices generally cover the content that is related to the learner's question and previously defined in the EPSS information base.

EPSS information base is formed by means of a database which will support whole system (LMS Database) and the special database of the EPSS to hold some necessary information about the content provided through the EPSS. This structure builds the data/information base of the EPSS. The system will have learning/training support facility because it is not a linear system; it is a self-directed one. Also, our system includes an online help/reference that supports the users on how to use the software easily. It has also an end-user interface to be able to make easy to use of the software. The system is a productivity system because the learners will be able to get some outputs of the pilot experiments on the equipments' screens.

In addition to these six components, our system will also have an assessment system that provides education of individual knowledge or skill and level of expertise either prior to performing a job or in assessing learner competency as shown in Fig. 3. The assessment part of the EPSS is developed on top of LMS assessment module [6].

\section{EPSS Structure}

EPSS structure of the ERRL project is developed on the pilot part of the project which is designed for Vector Network Analyzer (VNA) equipment of the laboratory. The EPSS can be reached from anywhere in the ERRL project. When the user needs something to learn about the VNA for example then clicks a link to be able to pass the EPSS part of the VNA. Fig. 4 is showing the VNA help system. The real picture of the equipments is used in the user interface panel and screen. The right side is blank at the beginning. If the learner needs to learn something about the buttons then it is enough to click on the buttons to see the explanations of that button (See Fig. 4, right part).

If the user needs some specific information about the VNA, then s/he can write the keyword or the question to the text field of "Search for:" part of the system (See Fig. 5). When the "Submit" button is clicked the results of the search will be shown in the right part of the system again. These results will be as links in the form of text documents, videos, audios or the other forms that are available in the Learning Management

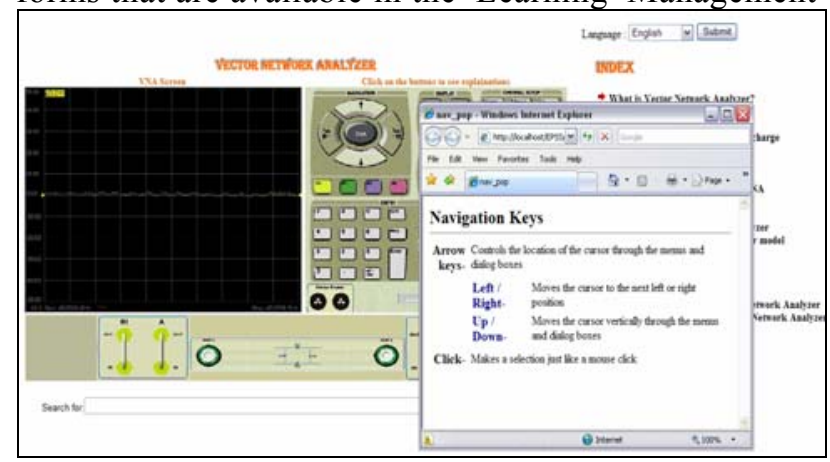

Figure 4. EPSS for ERRL (VNA Equipment)

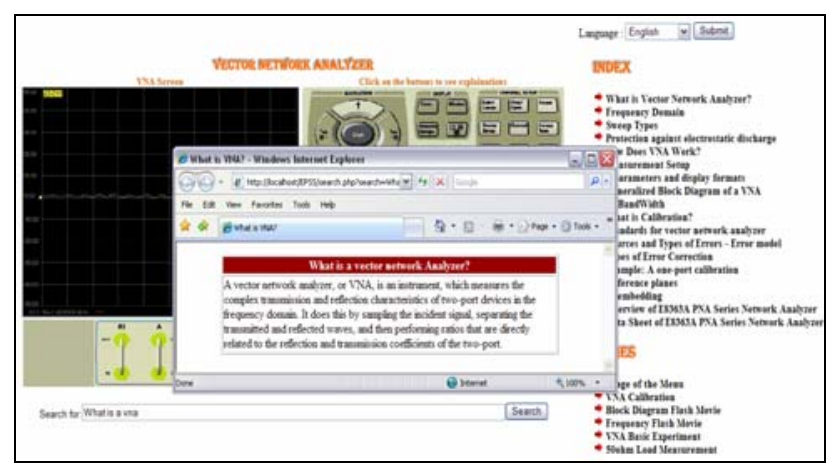

Figure 5. Searching with keywords

Systems' (LMS) database.

A basic experiment is also designed to practice how the equipment can be used within an experiment. This experiment is designed as a virtual one as simulating the real data that is previously taken from the equipment and stored in the database.

The language option is also generated in the pilot study. There are five language options (Turkish, English, German, French and Rumanian). When the user wants to change the language it is enough to select the language from the right top corner of the screen and then press the submit button. Then all the interface language and other links became to the selected language as seen in the Fig. 6 .

\section{Learning Management System (LMS)}

Moodle is an open source LMS used in the ERRL project. The content about the experiments is defined in the LMS. The LMS database and the ERRL information system database are linked together in order to support integration. 


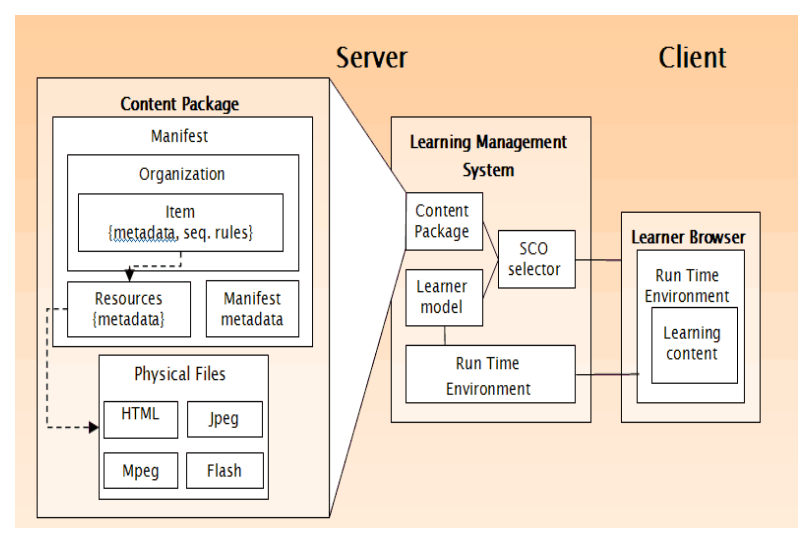

Figure 7. General Structure of Scorm Packets in ERRL LMS System

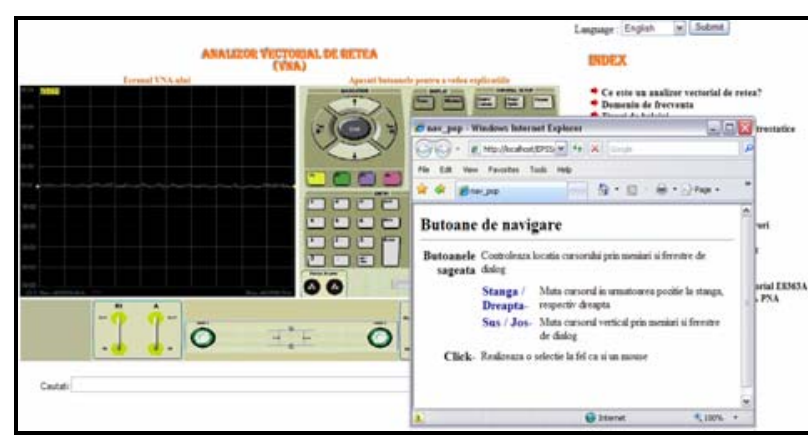

Figure 6. VNA in Romanian

\section{A.3 ERRL User Interface}

Learning Management System (LMS) is the main element that shapes the ERRL user interface. In the ERRL project, Moodle is used as an open source e-education tool. Moodle is an on-line course management system that can handle many required activities in a remote education site. The most important features of Moodle are that, it can be used by everybody (instructor, student) and it's having an advanced user interface [4]. Experiment interfaces, EPSS software and all the content about experiments have been embedded into this online course management software. Every learning object in the user interface (Experiment software, theoretical content, etc.) is added to the Moodle software as a Scorm object due to the standardization need of the system in any update or transfer (Fig. 7). SCORM is a set of specifications for developing, packaging and delivering high-quality education and training content/materials in web-based learning system whenever and wherever they are needed. [5]. Firstly, users and educators are added to the system with ERRL user interface. The user that $\log$ in to the system, learn own knowledge with skill level tests and own level in experimental setup. In the following steps, before users start the experiments, determination of users' knowledge about the measurement devices is performed. In the EPSS system, education about measurement devices and their basic usage is performed to the users not have a sufficient experience. Users having adequate knowledge start experiments.

\section{B. Experiments}

The ERRL laboratory provides several opportunities to the learners: -to learn about RF measurement methodology

- to interact with equipment

-to learn differences between low and high frequency measurements

- to compare analytical and experimental results

-to perform analysis on experimental data

-to asses of the learner's knowledge, skill and competency level

The technical content of the laboratory and instrumentation are designed to include sample subjects from analog/digital communications, electromagnetics, microwaves, antennas and propagation along with general RF technology. Since ERRL experiments include the concepts of reflection and transmission (return loss, Standing Wave Ratio, reflection coefficient), transmission lines, loss power, reflected power and transmitted power of the antennas, and the SWR, the input impedance of the antenna at the certain frequency range, multipath, noise, carrier, modulated carrier, modulation, time and frequency analysis of signals (Fourier analysis), electromagnetic compatibility measurements. Fig. 8 shows the pilot module of the ERRL.

The objective of the experiment is to observe the knowledge and ability level differs among individuals, experiments are also categorized vertically into three different skill levels: beginners, intermediate and advanced (Table I)

\section{B.1 Pilot Experiment: Measurement of Scattering Parameters of Devices}

This experiment was selected as pilot experiment. Software and hardware architecture of the system is developed on this pilot experiment. The objective of the experiment is to observe the concepts of reflection and transmission (return loss, standing wave ratio, reflection coefficient).

After a user logging on the ERRL webpage, the user can choose "Measurement of Scattering Parameters Experiment" from the experiment list table to conduct the remote experiment. Before conducting the experiment via internet, the user views Electronic Performance Support System (EPSS) which prepares the learners to be ready for doing the experiment with the VNA, the content about the experiment and "experiment" button to conduct the

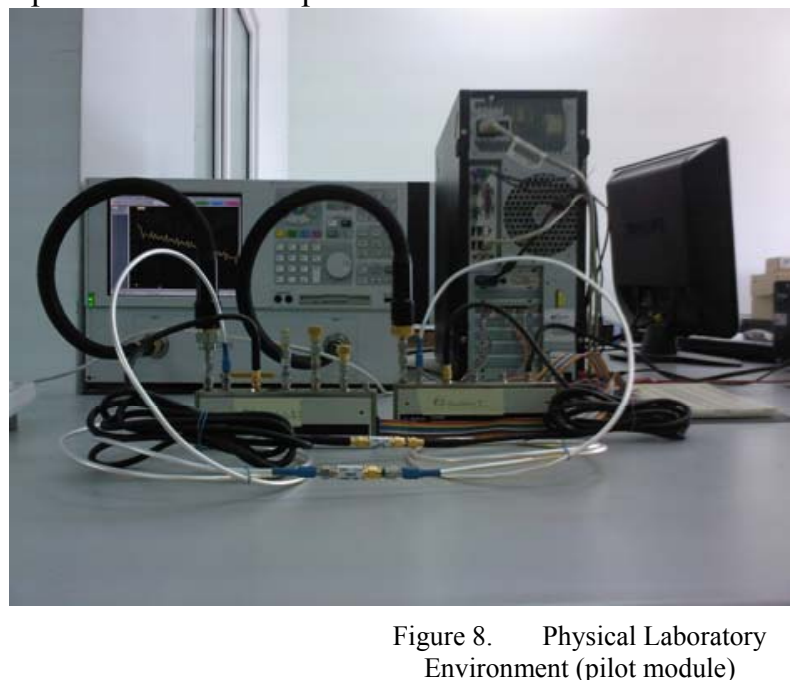


experiment. The user can click directly "experiment" button or after getting familiar with the VNA and/or the theoretical background of the experiment, the user can conduct the experiment by following the procedure of the experiment

As seen from Fig. 9, for the experiment on measurement of scattering parameters the user must set the frequency range and number of points. One of the scattering parameters must be chosen. User can measure the scattering parameters of one-port, two port or threeport high frequency devices. User can choose different display formats to represent the complex data.

Output data is available in a table and as a screen shot of a VNA screen (Fig. 10).

TABLE I.

EXPERIMENT LIST

\begin{tabular}{|c|c|c|c|}
\hline & Level 1 & Level 2 & Level 3 \\
\hline Basic Modules & $\begin{array}{l}\text { Basic } \\
\text { Measurements } \\
\text { with VNA } \\
\text { Spectrum } \\
\text { Analysis and } \\
\text { Fourier Series } \\
\text { EMC } \\
\text { Measurements }\end{array}$ & $\begin{array}{l}\text { Basic } \\
\text { Measurements } \\
\text { with VNA } \\
\text { Spectrum } \\
\text { Analysis and } \\
\text { Fourier Series } \\
\text { EMC } \\
\text { Measurements }\end{array}$ & $\begin{array}{l}\text { Basic } \\
\text { Measurements } \\
\text { with VNA } \\
\text { Spectrum } \\
\text { Analysis and } \\
\text { Fourier Series } \\
\text { EMC } \\
\text { Measurements }\end{array}$ \\
\hline $\begin{array}{l}\text { Antenna } \\
\text { Measurements }\end{array}$ & $\begin{array}{l}\text { Analysis of } \\
\text { antennas }\end{array}$ & $\begin{array}{l}\text { Analysis of } \\
\text { Antennas }\end{array}$ & $\begin{array}{l}\text { Analysis of } \\
\text { Antennas }\end{array}$ \\
\hline $\begin{array}{l}\text { RF and } \\
\text { Microwave } \\
\text { Measurements }\end{array}$ & $\begin{array}{l}\text { Large signal S } \\
\text { parameters } \\
\text { measurement } \\
\text { with scalar } \\
\text { test bench }\end{array}$ & $\begin{array}{l}\text { Extraction of } \\
\text { physical } \\
\text { parameters of } \\
\text { a coaxial } \\
\text { medium with } \\
\text { vector } \\
\text { network } \\
\text { measurement. } \\
\text { Measurement } \\
\text { of scattering } \\
\text { parameters of } \\
\text { devices }\end{array}$ & $\begin{array}{l}\text { Noise Fig. } \\
\text { measurement } \\
\text { of a spectrum } \\
\text { analyzer. }\end{array}$ \\
\hline $\begin{array}{l}\text { Radio } \\
\text { Communicatio } \\
\text { ns }\end{array}$ & $\begin{array}{l}\text { PLL in time } \\
\text { domain } \\
\text { Analog } \\
\text { Modulation } \\
\text { Frequency } \\
\text { Modulation }\end{array}$ & $\begin{array}{l}\text { FSK, ASK } \\
\text { and PSK } \\
\text { modulation }\end{array}$ & $\begin{array}{l}\text { Impulse } \\
\text { Response and } \\
\text { Multipath } \\
\text { Intermodulatio } \\
\mathrm{n} \\
\text { measurement } \\
\text { in RF systems }\end{array}$ \\
\hline
\end{tabular}

\section{B.2 Measurement of Open Circuit End, Short Circuit End and Scattering Parameters (s parameters) of $50 \Omega$ Load}

This experiment measures offset open and short, and 50 $\Omega$ load's scattering parameters on users' pre-defined frequency intervals (minimum $45 \mathrm{MHz}$ and maximum 40 $\mathrm{GHz}$ ). The measurements are allowed to plot in different display formats such as smith chart, log magnitude, linear magnitude, imaginary part, real part, group delay, SWR, phase and polar forms.

\section{CONCLUSION}

In contemporary circumstances, exponential importance of distance education increased the importance of internetbased education environments. ERRL is an important project that converts physical laboratory environment facilities into web based remote laboratory. In this study, the current situation of the pilot study of the ERRL project is defined. Educational outputs can not be reached due to the incompletion of the project. The system is planned to use by integrating with the current education programs in the following year. In spite it is not reached the educational outputs yet there will be strict outputs of the project such as the education given to students will become flexible without place and time constraint, there will be ability to perform more number of experiments, observation of students performance due to academic perspective will be easier and there will be decrease in possible accidents and hardware damages.

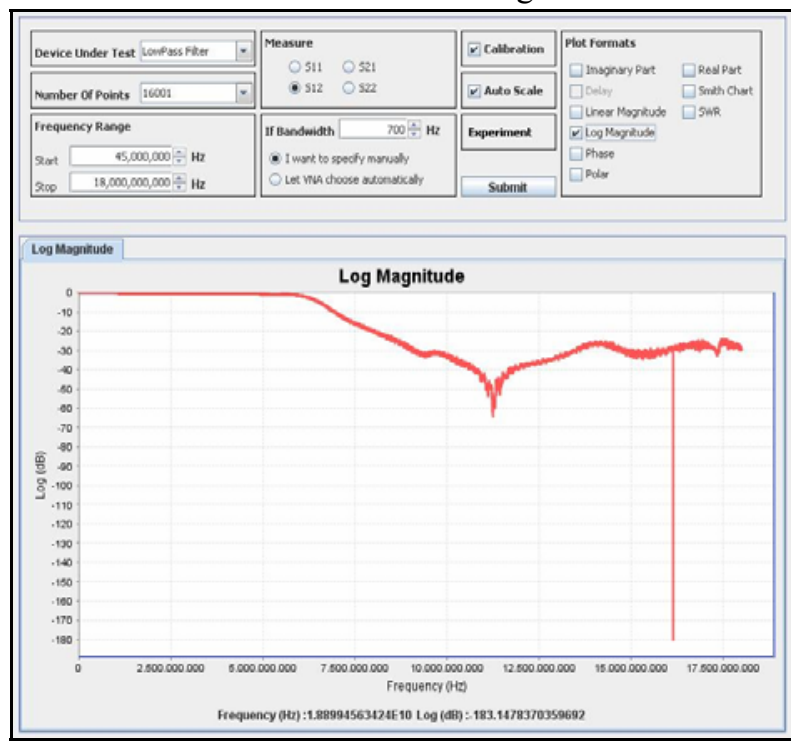

Figure 9. VNA in Internet-based Environment

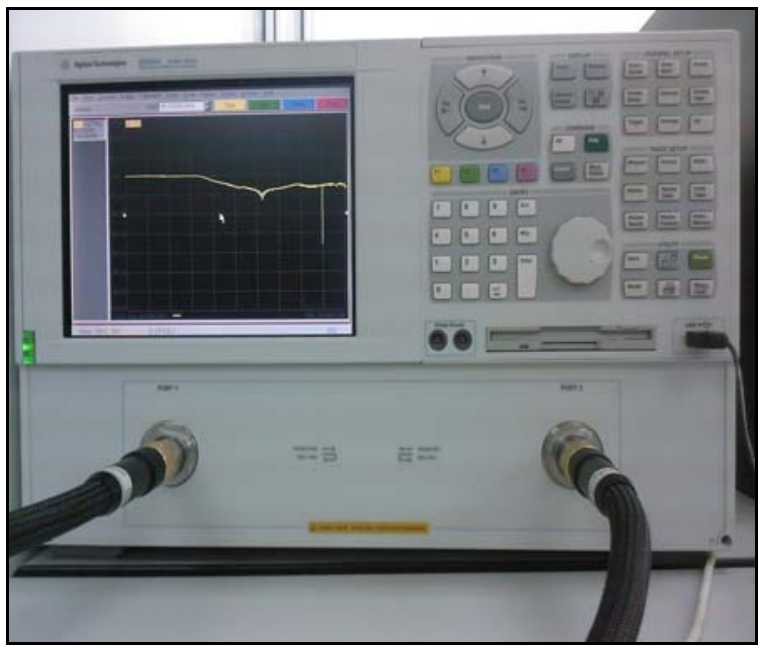

Figure 10. VNA

Enhanced pilot applications and experiments and the current state of the project that has been accomplished on this scope can be reached from (http://errlmoodle.atilim.edu.tr/) web address. Furthermore, detailed information about the project that is under scope of Leonardo Da Vinci Program and supported 
by European Union Commission can be reached from (http://errl.evtek.fi/) web site.

\section{REFERENCES}

[1] Sanchez, J., Dormino, S., Pastor, R., Morilla, F., “A JavA /Matlabbased environment for remote control system laboratories: Illustrated with an Inverted Pendulum", IEEE Transactions on Education, Vol. 47, No. 3, 2004

[2] Ko, C. C., Chen, B. M., Chen, S. H., Ramakrishnan, V., Chen, R., $\mathrm{Hu}, \mathrm{S}$. Y., Zhuang, Y., "A web-based virtual laboratory on a frequency modulation experiment”, IEEE Trans. On systems, man and cybernetics-part c: applications and reviews, Vol. 31, No. 3, August 2001.
[3] Cagiltay, N.E., Aydin, E., Oktem, R., Kara, A., Alexandru, A., Reiner, B. (2008). Requirements on Remote RF Laboratory Applications: An Educators' Perspective, Accepted for publication, IEEE Transactions on Education.

[4] Merrick, C.M and J.W. Ponton (1996). The ecosse control hypercourse. Computers in Chemical Engineering 20, Supplement, pp. 1353-1358.

[5] http://moodle.org/blog/index.php?filtertype $=$ course \&filterselect $=5$ \&tagid $=164$

[6] Chang, C.C. "The Relationship between the Performance and the Perceived Benefits of using an Electronic Performance Support System", Innovations in Education and Teaching International, Vol. 41, No. 3, August 2004. 